\title{
A (I)LEGALIDADE DA CONTRATAÇÃO DIRETA DE PESSOAL E DISPENSA DE LICITAÇÕES PELOS CONSÓRCIOS PÚBLICOS INTERMUNICIPAIS
}

\section{THE (IL) LEGALITY OF DIRECT CONTRACTING OF STAFF AND WAIVER OF BIDDINGS BY INTERMUNICIPAL PUBLIC CONSORTIUMS}

\section{Renan Plinio Linhares ${ }^{1}$}

Resumo: Os serviços públicos são funções realizadas pelo Estado e seus entes federados, e é obrigação desses entes prestá-los da forma mais eficaz e eficiente possível. Os consórcios públicos são formas de união entre entes federados, cujo objetivo é prestar algum tipo de serviço que um ente, em sua singularidade, teria dificuldades em prestar. Entretanto, há muitas dúvidas por parte dos gestores acerca da necessidade de seguir os preceitos pú- blicos no tocante à contratação de pessoal e contratação de serviços indiretos via licitação, principalmente naqueles consórcios criados anteriormente a 2005. O presente artigo, de forma exploratória, busca examinar a viabilidade de licitação e contratação direta por parte desses consórcios, analisando como é feita a cooperação entre entes, a natureza jurídica dos consórcios públicos e seus tipos e suas formações. Para tanto, utiliza-se do método dedutivo

1 Bacharel em Direito pela Universidade do Extremo Sul Catarinense (UNESC). Pós-Graduado em Direito Constitucional e Administrativo pela Escola Paulista de Direito (EPD) e PósGraduado em Gestão Pública Municipal pelo Instituto Federal de Santa Catarina (IFSC). Pós-Graduando em Direito Público pela UNISUL/ESMESC/AMC. Advogado e Servidor Público Municipal. E-mail: rplinhares@gmail.com 
para abordar o assunto, utilizando, como principais documentos de estudo, a doutrina, a jurisprudência e a lei. Discute-se os documentos utilizados na concepção do trabalho, trazendo, ao final, a análise acerca da necessária utilização, por meio dos consórcios públicos, dos preceitos públicos fundamentais inerentes à administração pública.

Palavras-Chave: Consórcios públicos. Licitação. Contratação direta.

Abstract: Public services are functions performed by the State and its federated entities and it is the obligation of these entities to provide them in the most effective and efficient way possible. Public consortia are forms of union among federated entities, whose purpose is to provide some kind of service that an entity, in its singularity, would have difficulties to provide. However, there is a great deal of doubt among managers about the need to follow public precepts regarding the hiring of personnel and the contracting of indirect services through bidding, especially in those consortia created prior to 2005. This exploratory article seeks to examine the feasibility of bidding and direct contracting by these consortia, analyzing how cooperation is made between entities, the legal nature of public consortia and their types and formations. To do so, it uses the deductive method to approach the subject, using, as main study documents, the doctrine and jurisprudence. It discusses, in a specific way, the documents used in the conception of the work, bringing, in the end, the analysis about the necessary use, through the public consortia, of the fundamental public precepts inherent to the public administration.

Keywords: Public Consortia. Biddings. Direct contracting.

\section{INTRODUÇÃO}

Com o advento da Lei $\mathrm{n}^{\circ} 11.075 / 05$, foram trazidos para o ordenamento jurídico brasileiro os chamados consórcios públicos. Os consórcios públicos são conceituados como um mecanismo de cooperação intergovernamental horizontal, sendo, dessa maneira, compostos por entes de mesmo nível de governo ou diferentes, visando uma colaboração conjunta 
em busca de um interesse mútuo (COUTINHO, 2006, p. 450; MAZZA, 2012, p. 377-378).

Os consórcios não se confundem como contratos administrativos entre entes federados. Nestes, os contratantes possuem interesses opostos enquanto, no consórcio público, os entes possuem interesse de igual teor (ALEXANDRE; DEUS, 2015, p. 2).

Grave é a questão acerca da natureza jurídica dos consórcios públicos. Há muitas dúvidas e muitas opiniões diferentes acerca do que é o consórcio público e como ele deve ser gerido. O mais grave dos problemas encontra-se na dúbia questão do concurso público, principalmente nos consórcios anteriormente criados pela Lei $\mathrm{n}^{\circ} 11.075 / 2005$.

Com base no disposto acima e visando solucionar um problema que atinge boa parte dos municípios que faz parte de um consórcio, propõe-se os seguintes objetivos para o trabalho:

O objetivo geral do presente trabalho consiste em analisar o consórcio público, buscando um exemplo real, com o fim de analisar se a possibilidade de contratação de pessoal pode ser direta ou se deverá ser realizado concurso público para tal, bem como analisar se esses consórcios são obrigados a realizar licitação ou se são dispensados.

Assim, tem-se como questão a ser discutida, no presente trabalho, o seguinte: podem os consórcios públicos intermunicipais de saúde contratarem pessoal e serviços sem a necessidade de observância aos princípios públicos aplicáveis à administração indireta?

Baseado no objetivo geral, tem-se como necessária a busca dos seguintes objetivos específicos:

a. mostrar um breve entendimento sobre o que é a cooperação entre entes federados; 
b. apresentar o conceito de consórcios públicos e qual a sua natureza jurídica; e

c. expor os diversos tipos de consórcios públicos; como são realizadas suas formações; e a inerente necessidade de respeitar os princípios públicos.

Para alcançar os objetivos propostos, será utilizado o método exploratório, de cunho quantitativo, utilizando-se o método dedutivo para o alcance dos resultados pretendidos.

$\mathrm{O}$ artigo está dividido da seguinte forma: $\mathrm{O}$ primeiro capítulo abrange a introdução e a fundamentação teórica. $\mathrm{O}$ segundo capítulo aborda a metodologia, que, no presente caso, se utiliza o método dedutivo de cunho exploratório. $\mathrm{O}$ terceiro capítulo mostra os resultados da pesquisa. O quarto capítulo apresenta discussões sobre o que foi encontrado nos documentos estudados. E o último e quinto capítulo traz a conclusão do trabalho.

Dessa forma, será possível estabelecer uma ideologia sobre o que é o consórcio público e a capacidade de analisar se os consórcios públicos devem ou não seguir aquilo que é inerente aos entes públicos.

\section{FUNDAMENTAÇÃO TEÓRICA}

\subsection{Da cooperação entre os entes}

O homem é notadamente um ser social. Para atender a essa necessidade, é necessário que haja a cooperação de outras pessoas. Pensando em um exemplo simples, seria possível a construção das pirâmides do Egito sem a cooperação de diversos seres que contribuíram, da sua maneira, para a aquisição do produto? (ALEXANDRE; DEUS, 2015, p. 1).

A administração pública não é diferente. Assim, em razão de muitas situações que são custosas para o ente federado, a 
administração pública veio se adaptando e criando maneiras para executar serviços mais dificultosos mediante a união de esforços ou de recursos (ALEXANDRE; DEUS, 2015, p. 3).

A ampliação das funções estatais, juntamente com a complexidade e o custo das obras públicas, vem exigindo novas formas e meios de prestação de serviço cuja responsabilidade é do Estado. Desse modo, é necessário que haja colaboração entre os entes federativos, visando um maior alcance dos referidos serviços. Dá-se, assim, o surgimento de institutos, como os convênios públicos, os consórcios administrativos (consórcios públicos) e as parcerias público-privadas (MEIRELLES, 2015, p. 472-473).

Nos últimos 15 anos, quando se fala em cooperação entre os entes federados, os consórcios públicos têm sido a forma preferida de instrumentalização dessa ação. Em face desse instituto, houve a necessidade de sua formalização com a EC $n^{\circ} 19 / 98$ e com a Lei $n^{\circ} 11.107 / 05$, regulamentadoras dos consórcios públicos. O consórcio público, portanto, começou a ganhar novos ares no Brasil (MADEIRA; MADEIRA; MADEIRA, 2013, p. 512).

\subsection{Consórcios públicos e sua natureza jurídica}

Inicialmente, entendia-se que os consórcios públicos são conceituados, pela maioria de seus estudiosos, como um mecanismo de cooperação intergovernamental horizontal, sendo, dessa forma, composto por entes de mesmo nível de governo, visando uma colaboração conjunta no alcance de objetivos de interesse mútuo (COUTINHO, 2006, p. 450; MAZZA, 2012, p. 377-378).

O passo fundamental para o crescimento da articulação federativa entre os seus próprios entes foi a redação trazida no art. 241 da CRFB/88, na Emenda Constitucional n ${ }^{\circ} 19$, de 1998, que alterou o próprio art. 241 (BALDISSERA, 2015, p.14). 
Assim dispõe o art. 241 da CRFB/88:

Art. 241. A União, os Estados, o Distrito Federal e os Municípios disciplinarão por meio de lei os consórcios públicos e os convênios de cooperação entre os entes federados, autorizando a gestão associada de serviços públicos, bem como a transferência total ou parcial de encargos, serviços, pessoal e bens essenciais à continuidade dos serviços transferidos. (BRASIL, 1988).

Como se pode observar, a norma constitucional previa a criação de uma lei que a regulamentasse, disciplinando o funcionamento dos consórcios públicos e dos convênios de cooperação. Dessa forma, visando um norte para a administração pública nesse âmbito e seguindo a competência atribuída no art. 22, inc. XXVII, que prevê a competência da união de legislar sobre normas gerais de contratação e licitação para a administração pública, coube à esta a edição da referida lei. Assim, em 2005, a União editou a Lei n ${ }^{0}$ 11.075/05, sendo esta a que norteia a constituição dos consórcios públicos em âmbito nacional (BALDISSERA, 2015, p.15).

Di Pietro (2005, p. 3) afirma que o objetivo da norma constitucional é o de consolidar a gestão associada entre os entes, visando à implementação ou à consecução de fins de interesse comum. Normalmente, o serviço que um ente não pode exercer sozinho torna-se mais fácil com a participação dos demais entes.

Salienta-se que o dispositivo constitucional não é, de todo modo, inovador, visto que a constituição de 1967 trazia, em seu art. 13, § 3, o seguinte: “A União, os Estados e Municípios poderão celebrar convênios para execução de suas leis, serviços ou decisões, por intermédio de funcionários federais, estaduais ou municipais.” (BRASIL, 1967).

Madeira, Madeira e Madeira (2013, p. 510) seguem na mesma linha e afirmam que o novo texto constitucional visa 
à gestão compartilhada de serviços públicos. Menciona também que os entes federados poderão realizar consórcios públicos e convênios de cooperação, o que torna suficiente entender que os consórcios podem contar com a participação de diferentes entes da federação.

Antes da promulgação da Lei $\mathrm{n}^{0} 11.107 / 05$, havia certo consenso doutrinário em considerar o convênio e o consórcio como acordos de vontade, sendo o consórcio utilizado quando os entes consorciados eram do mesmo nível (consórcio entre Municípios ou entre Estados) e o convênio quando se tratava de entidades de níveis diferentes, como, por exemplo, os convênios entre União e Estados ou Municípios, ou entre Estados e Municípios (DI PIETRO, 2005, p. 4).

Com o advento da Lei de $\mathrm{n}^{\circ} 11.075 / 05$, mudou-se a questão conceitual acerca de que o consórcio deve ser formado apenas por entes do mesmo nível de governo, podendo fazer parte de consórcios quaisquer entes federados, como Estados, Municípios e até a própria União (COUTINHO, 2006, p. 2).

Di Pietro (2005, p. 2-3) faz severas críticas à Lei $n^{\circ}$ 11.075/05, começando pela incongruência trazida pelo legislativo no preâmbulo da Lei e no corpo dela. No preâmbulo, dispõe o seguinte: "normas gerais de contratação de consórcios públicos". Já no seu corpo, a Lei não traz normas para contratação, mas sim de constituição de pessoas jurídicas, que se dá por meio de um procedimento com diversas fases. $\mathrm{O}$ contrato, que se refere ao preâmbulo, é apenas uma parte de toda a norma.

De acordo com Alexandre e Deus (2015, p. 311), os consórcios públicos não se confundem com contratos administrativos entre entes federados. Nestes, os contratantes têm interesses opostos, enquanto, no consórcio público, os entes possuem interesses de igual teor. 
Auxiliando na diferenciação, o Decreto federal n. 6017/2007, que trata sobre normas gerais para a União, os Estados, o Distrito Federal e os Municípios contratarem consórcios para o alcance de objetivos comuns, dispôs, em seu art. $2^{\circ}$, inc. I, o conceito de consórcio público, conforme a seguinte transcrição:

Art. $2^{\circ}$ Para os fins deste Decreto, consideram-se:

I - consórcio público: pessoa jurídica formada exclusivamente por entes da Federação, na forma da Lei $n^{\circ}$ 11.107, de 2005, para estabelecer relações de cooperação federativa, inclusive a realização de objetivos de interesse comum, constituída como associação pública, com personalidade jurídica de direito público e natureza autárquica, ou como pessoa jurídica de direito privado sem fins econômicos. (BRASIL, 2007).

Alexandre e Deus (2015, p. 312) também salientam que, no consórcio, não existe a bilateralidade, uma vez que podem existir diversos consorciados dentro de um mesmo consórcio.

Moreira Neto (2014, p. 98) afirma que os consórcios públicos são muito populares e eficientes em países europeus, entretanto, no Brasil, não possuem tanto desenvolvimento. $\mathrm{O}$ fato de isso acontecer é em razão da falta de investimentos, uma vez que o Brasil é um país de administração indireta pesada, dispendiosa e hipertrofiada e de administração direta burocratizada e atomizada.

Muitos estudiosos de renome, como Hely Lopes de Meirelles e Victor Nunes Leal, tentaram, insistentemente, dar um tratamento legislativo concreto para os consórcios públicos privados. Entretanto, apenas com a publicação da Lei $n^{\circ} 11.107$, de 2005, é que os entes federados tiveram uma legislação específica para a concreção de consórcios públicos. Contudo, não são obrigados a se pactuarem conforme tal regra, podendo, no uso de suas prerrogativas autonômicas, poderem se consorciar 
da forma mais dispendiosa e conveniente a seus propósitos (MOREIRA NETO, 2014, p. 99).

De acordo com Meirelles (2016, p. 306-307), os consórcios públicos são formados mediante contrato de consórcio público, que é o ajuste que os entes federados celebram, precedidos de protocolo de intenções e aprovação legislativa. Nesses contratos, os entes delegam a gestão associada de serviços e a realização de objetivos comuns, em conformidade com a legalidade. Ainda definem a sua formação, se associação de direito público ou como pessoa jurídica de direito privado, sem fins econômicos.

\subsection{Tipos de consórcios públicos}

Basicamente, existem dois tipos de consórcios públicos, segundo Mazza (2012, p. 747), que são divididos em dois grupos: a) consórcios públicos convencionais; e b) consórcios públicos regidos pela Lei $\mathrm{n}^{\circ}$ 11.107/05.

O ilustre Meirelles (2016, p. 473) assevera que:

Os consórcios públicos são pessoas de direito público, quando associação pública, ou de direito privado, decorrentes de contratos firmados entre entes federados, após autorização legislativa de cada um, para a gestão associada de serviços públicos e de objetivos de interesse comum dos consorciados, através de delegação e sem fins econômicos. Trata-se de gestão associada ou cooperação associativa de entes federativos, para a reunião de recursos financeiros, técnicos e administrativos - que cada um deles, isoladamente, não teria -, para executar o empreendimento desejado e de utilidade geral para todos.

Madeira, Madeira e Madeira (2013, p. 512) afirmam que: o consórcio público surge como uma nova espécie de pessoa jurídica, consubstanciada de personalidade jurídica, consubstanciada de personalidade própria e autônoma, a 
quem é investido para a execução das tarefas de competência própria dos entes federados. Poderá também praticar atos em nome próprio, participando diretamente das relações jurídicas e constituir patrimônio específico.

Além disso, reiterando o que foi trazido pela norma e o apresentado por Mazza (2012, p. 747), Madeira, Madeira e Madeira (2013, p. 512) afirmam o seguinte acerca das modalidades de consórcio:

Essa modelagem pode ocorrer segundo duas modelagens previstas na lei: ou associação pública com personalidade jurídica de direito público, ou pessoa jurídica de direito privado com personalidade jurídica de direito privado. Quando revestir-se de personalidade jurídica de direito público, integrará a administração pública indireta de todos os entes federados consorciados. Ao apresentar-se mediante a personalidade de direito privado, observará as normas de direito público atinente à realização de licitação, celebração de contratos, prestação de contas e admissão de pessoal, os quais serão regidos pela Consolidação das Leis do Trabalho (art. $6^{\circ}$, parágrafos $1^{\circ}$ e $2^{\circ}$, da Lei $\left.n^{\circ} 11.107 / 05\right)$.

Entretanto, contrariando a ideia exposta, Di Pietro (2005, p. 4-5) afirma que, embora essa regra seja trazida apenas aos consórcios públicos de direito público, sábio é afirmar que a regra valerá para os consórcios de direito privado. Não há como criar uma pessoa jurídica própria para realizar funções do estado e deixá-la de fora da estrutura administrativa. Qualquer ente que seja criado deve pertencer ou à administração direta (se órgão) ou à indireta (se instituído com personalidade jurídica).

Di Pietro (2005, p. 4) afirma que, se o consórcio público tiver personalidade de direito privado, se regerá pelo direito civil em tudo o que não for expressamente derrogado por normas de direito público, tal como ocorre com as fundações go- 
vernamentais instituídas com personalidade de direito privado e com as empresas estatais. A própria lei, inclusive, derroga parcialmente o direito privado em prol do direito público. Especificamente, o direito privado é derrogado quando o art. $6^{\circ}, \S$ $2^{\circ}$, determina a sujeição dos consórcios com personalidade de direito privado às normas sobre licitação, celebração de contratos, prestação de contas e admissão de pessoal.

A criação de um consórcio público de direito privado deve ser permitida pelo contrato de consórcio, no qual deve ser especificado as regras básicas de seu estatuto social e a forma jurídica imposta. $\mathrm{O}$ consórcio ganha legitimidade a partir da sua inscrição de seu estatuto, acompanhado da nomeação dos seus respectivos membros da Assembleia Geral e da ata no Registro Civil de Pessoas Jurídicas (BRASIL, 2014, p. 8).

Souza (2012, p. 19) afirma que existem diversas figuras jurídicas possíveis e que fazem parte do ordenamento jurídico brasileiro e que não são consórcios públicos, mas possuem diversos pontos de congruência.

Ressalta-se o instituto criado pela Lei $\mathrm{n}^{\circ}$ 6.404/76, que disciplinou, em seu art. 278, a possibilidade de criação de uma figura associativa nomeada de "consórcio". Porém, não se confunde com o consórcio público, visto que se caracteriza por uma associação temporária entre pessoas jurídicas, visando à realização de um objeto determinado e específico, que não possui personalidade jurídica própria. Esse instituto é comumente chamado de "consórcio privado", embora seja um erro (SOUZA, 2012, p. 19).

Souza (2012, p. 20) ensina que esse tipo de consórcio foi amplamente utilizado pela própria Administração Pública, sendo que, quando utilizado por esta, não desempenhava nenhuma atividade lucrativa, mas a prestação de algum tipo de serviço público à população local. Antes da Lei no 11.107/05, 
essa era uma alternativa comum a ações desempenhadas pelo Sistema Único de Saúde (SUS). Ressalta-se que esses tipos de consórcios ainda são amplamente difundidos na área da Saúde, sendo grandes responsáveis por bons resultados na gestão de recursos técnicos e humanos.

Corroborando com o disposto pela Lei ${ }^{\circ} 6.404 / 76$, a Lei $n^{\text {o }} 8080 / 91$ trouxe, em seu art. 10, a possibilidade de criação de consórcios intermunicipais para desenvolver em conjunto as ações e os serviços de saúde relativos a eles. Frisa-se que a Lei dispõe que os consórcios deverão obedecer ao princípio da direção única, que está previsto no art. $9^{\circ}$ da mesma normativa (BRASIL, 1990).

Grande confusão é causada quando se refere a esses consórcios de direito privado, criados antes da Lei $\mathrm{n}^{\circ}$ 11.107/05. Porém, boa parte da doutrina os classificam como tendo natureza autárquica (DI PIETRO, 2018, p. 436).

A Lei $\mathrm{n}^{\circ} 11.107 / 05$ dispõe que o regime de pessoal do consórcio público de direito privado é o celetista, sendo seus cargos providos por meio do instituto do concurso público. No tocante aos consórcios públicos de direito público, a lei omite-se. No entanto, por analogia, admite-se o previsto no art. 39, caput, da CRFB/88, no qual se estabelece que o regime jurídico seria o estatutário. Porém, certo é afirmar que, no regime estatutário, o vínculo criado é com o Estado, gerando estabilidade, de um regime previdenciário diferenciado, bem como vários outros benefícios. Assim, diante da dificuldade de criação de estatuto para entidade do consórcio público de direito público, é correto afirmar que o regime jurídico da associação de Direito Público é o celetista, uma vez que se torna impossível contratar estatutários, visto que estes não serão vinculados a nenhum ente específico (BRASIL, 2012, p. 18). 
Corroborando com a ideia, Mazza (2012, p. 382) assim ensina:

Se o consórcio tiver personalidade jurídica de direito privado, estará adstrito às normas de direito público no que concerne à realização de licitação, celebração de contratos, prestação de contas e admissão de pessoal, que será regida pela CLT.

Além do concurso, como mostrado anteriormente, é possível que os entes federados formadores e associados ao consórcio possam ceder seus servidores a este, conforme estabelece a Lei no 11.107/05 (BRASIL, 2012, p.19).

A Lei $\mathrm{n}^{\circ} 11.107 / 05$ criou três tipos de contratos: o contrato de consórcio, o contrato de rateio e o contrato de programa (MALMEGRIN, 2014, p. 100).

Malmegrin (2014, p. 100) explana o seguinte acerca do contrato de consórcio: "O contrato de consórcio é celebrado entre os entes consorciados e seu conteúdo contempla as principais regras da associação. Uma assembleia geral de fundações do consórcio público define os estatutos."

Malmegrin (2014, p. 100) afirma que os consórcios públicos são objetos de discussão entre juristas e administradores, tendo em vista os aspectos de suas legalidades. Porém, no tocante à eficácia, têm se demonstrado com resultados bastante efetivos e promissores.

\section{METODOLOGIA}

Este estudo se baseia em uma forma de pesquisa quantitativa de cunho exploratório, por meio de pesquisas em doutrinas, artigos e jurisprudência, baseando-se no método dedutivo para a obtenção dos resultados do presente estudo.

A pesquisa exploratória é aquela que é realizada em áreas na qual se existe pouco conhecimento acumulado e sistemati- 
zado. Por ter natureza de sondagem, não abarca hipóteses que poderão surgir ou não durante ou ao final da pesquisa (VERGARA, 2009, p. 42). A pesquisa quantitativa, segundo Creswell (2007, p. 184 e 188), é aquela em que os indivíduos "se baseiam em dados e texto de imagem, têm passos únicos na análise de dados e usam estratégias diversas de investigação".

Como ensinam Prodanov e Freitas (2013, p. 27):

O raciocínio dedutivo tem o objetivo de explicar o conteúdo das premissas. Por intermédio de uma cadeia de raciocínio em ordem descendente, de análise do geral para o particular, chega-se a uma conclusão. Usa o silogismo, a construção lógica para, a partir de duas premissas, retirar uma terceira logicamente decorrente das duas primeiras, denominada de conclusão.

A pesquisa atual foi feita baseada na jurisprudência pátria, na legislação pátria e na doutrina. No tocante à aquisição de tais documentos, ressalta-se a facilidade. Todos os documentos utilizados são amplamente disponíveis, tanto na internet quanto em bibliotecas locais. Os livros utilizados são de divulgação ampla, sendo utilizados frequentemente por parte dos professores nas universidades.

\section{RESULTADOS}

Os consórcios públicos, conforme já exposto, são aqueles entes formados pela união de entes federados, sendo estes $\mathrm{Mu}-$ nicípios, Estados, Distrito Federal e União.

Assim, a presente pesquisa buscou examinar a melhor maneira de analisar se os preceitos públicos norteiam os consórcios públicos, em especial aqueles voltados para a área da Saúde.

Analisando os entendimentos doutrinários, Di Pietro (2018, p. 436) afirma o seguinte: 
Seja qual for a maneira de administração do consórcio, ele estará gerindo dinheiro público e serviço público. Por isso mesmo, as suas contratações de pessoal dependem de concurso público e os contratos de obras, serviços, compras e alienações dependem de licitação.

Entende-se, assim, de forma simplista, que, independentemente de como é feita a formação do consórcio público, se de direito público ou de direito privado, ele gerirá dinheiro público, logo estará sujeito a preceitos públicos relacionados aos entes públicos fora da administração direta.

No tocante à admissão de pessoal desses entes criados anteriormente à Lei $n^{0}$ 11.107/05, grande é a confusão. Existem diversas divergências acerca da necessidade de concurso público ou não, principalmente por parte dos próprios consórcios. Entretanto, a jurisprudência vem se firmando em uma posição.

Além disso, é importante ressaltar a necessidade de observação da Súmula 363 do TST, que dispõe que:

CONTRATO NULO. EFEITOS. A contratação de servidor público, após a $\mathrm{CF} / 1988$, sem prévia aprovação em concurso público, encontra óbice no respectivo art. 37 , II e $\S 2^{\circ}$, somente lhe conferindo direito ao pagamento da contraprestação pactuada, em relação ao número de horas trabalhadas, respeitado o valor da hora do salário mínimo, e dos valores referentes aos depósitos do FGTS. (BRASIL, 2003, p. 1).

Nos julgados, os Tribunais vêm entendendo de forma similar como tratar a questão dos consórcios públicos, no tocante à questão da necessidade de concursos públicos e licitações.

O Tribunal Regional do Trabalho da $3^{\circ}$ Região entendeu, mediante uma reclamação trabalhista, que o contrato de trabalho de Consórcios Intermunicipais de Saúde é considerado nulo se não for precedido por concurso, conforme a ementa: 
CONSELHOS INTERMUNICIPAIS. NATUREZA JURÍDICA AUTÁRQUICA. AUSÊNCIA DE CONCURSO PARA ADMISSÃO DE PESSOAL. CONTRATO NULO. EFEITOS. A jurisprudência trabalhista atribui natureza autárquica aos Conselhos Intermunicipais, o que os obriga ao concurso público para admitir trabalhadores. Descumprida esta exigência legal, o contrato de trabalho é considerado nulo, sendo devidos ao trabalhador os salários e o FGTS do período da prestação dos serviços. (BRASIL, 2009).

Corroborando com a jurisprudência anterior, o mesmo Tribunal trouxe à tona, em julgado recente, jurisprudência de valoração semelhante:

CONSÓRCIO DE MUNICÍPIOS - CONTRATAÇÃO DE EMPREGADO SEM A PRÉVIA APROVAÇÃO EM CONCURSO PÚBLICO - NULIDADE. - Consórcio administrativo, constituído por Municípios a partir de Protocolo de Intenções, sob a forma jurídica de associação pública, detendo, portanto, personalidade jurídica de direito público e natureza autárquica, na forma do artigo $6^{\circ}$ da Lei n. 11.107/2005, deve se ater às normas de direito público, inclusive no que respeita à admissão de pessoal, de forma que a contratação necessariamente deve ser precedida de regular aprovação em concurso público, sendo nulos, portanto, os contratos firmados contrariamente aos ditames do art. 37 , II e $\S 2^{\circ}$, da Constituição Federal. Os efeitos pecuniários, na hipótese, ficam limitados àqueles previsto na Súmula 363 do col. TST. (BRASIL, 2018).

O Tribunal Regional do Trabalho da $15^{\mathrm{a}}$ Região entendeu de forma semelhante, conforme a seguinte ementa:

CONSÓRCIO INTERMUNICIPAL. CONTRATAÇÃO SEM CONCURSO PÚBLICO. São inafastáveis os princípios da legalidade e da moralidade administrativa a que 
se sujeitam os entes públicos participantes do consórcio público regido pelo artigo 241 da Constituição Federal, restando nulo o contrato de trabalho não precedido de concurso público, nos termos da Súmula 363 do C. TST e do artigo 37, II, da Constituição Federal. Aplicação do artigo $6^{\circ}$ da Lei 11.107/2005. Recurso da reclamante ao qual se nega provimento. (BRASIL, 2006).

Importante salientar também o entendimento do Tribunal de Contas do Estado de Minas Gerais em uma consulta pública feita pelo Prefeito do Município de Cristiano Otoni acerca do assunto (MINAS GERAIS, 2013).

A referida consulta pública indagou duas questões: se as entidades consorciais ou os consórcios criados antes da vigência da Lei federal $n^{\circ} 11.107 / 2005$ devem se adaptar aos termos da própria Lei e se os consórcios públicos podem adotar o regime jurídico estatutário de seus servidores.

No tocante ao primeiro questionamento, entendeu o referido Tribunal de Contas que os consórcios criados anteriormente à Lei $n^{\circ} 11.107 / 05$ não se tornam obrigados à adotarem as regras da nova legislação dos consórcios públicos, embora seja possível a sua transformação, caso queiram. Salienta-se que tal situação não abre brecha para a criação de consórcios à margem da Lei $\mathrm{n}^{\mathrm{o}} 11.107 / 05$, sob pena de o gestor sofrer por ato causador de improbidade administrativa (MINAS GERAIS, 2013).

No tocante à segunda questão, o Tribunal de Contas entendeu que tanto o consórcio público com personalidade de direito público quanto o consórcio de direito privado devem obrigatoriamente adotar o regime celetista, sempre com a prévia aprovação em concurso público, sendo, porém, admitida a cessão de servidores pelos entes consorciados, estando estes vinculados à forma de contratação originária (celetista ou estatutário) (MINAS GERAIS, 2013). 
Extrai-se do julgado a seguinte ementa:

EMENTA: CONSULTA - PREFEITO - CONSÓRCIOS PÚBLICOS - I. ENTIDADES CONSORCIAIS CRIADAS ANTES DE 06/04/2005 - APLICABILIDADE DA LEI N. 11.107/2005 - NÃO OBRIGATORIEDADE - II. QUADRO PRÓPRIO DE PESSOAL - CONCURSO PÚBLICO - EMPREGADOS PÚBLICOS - REGIME CELETISTA - III. CESSÃO - SERVIDORES PÚBLICOS ESTATUTÁRIOS REGIME LABORAL DE ORIGEM - POSSIBILIDADE 1. A Lei Federal n. 11.107/2005, por determinação expressa do seu art. 19, não atinge os consórcios ou entidades consorciais criados antes de sua vigência. 2. Independentemente da personalidade jurídica adotada no consórcio público, seu quadro de pessoal será ocupado por empregados celetistas concursados e/ou excepcionalmente por servidores públicos cedidos pelos entes da Federação consorciados, permanecendo vinculados ao seu regime laboral de origem, celetista ou estatutário (art. 23 do Decreto Federal n. 6.017/2007) (MINAS GERAIS, 2013).

Os consórcios públicos de direito privado devem respeitar as regras que incidem sobre a administração indireta do Poder Executivo. Assim, em observância ao art. $6^{\circ}, \S 2^{\circ}$, da Lei n ${ }^{\circ} 11.107 / 05$, extrai-se que o consórcio público se sujeita ao princípio do concurso público; sujeita-se ao controle interno e externo dos órgãos de controle do Poder Executivo (BRASIL, 2012, p. 9).

\section{DISCUSSÕES}

Os consórcios públicos no Brasil não são recentes, pelo menos não a sua efetiva implementação.

A Lei ${ }^{0} 11.107 / 2005$ trouxe várias novidades em relação à constituição desses consórcios públicos, e o Decreto federal 
$\mathrm{n}^{\mathrm{o}}$ 6.067/2007 regulamentou o modus operandi dos consórcios públicos.

Entretanto, os entes federados, principalmente os Municípios, possuem grande confusão acerca do que pode ou não pode ser realizado, sobretudo no tocante à necessidade de licitação e realização de concursos públicos. Mais confuso ainda se torna quando se discute acerca dos consórcios criados anteriormente à Lei $n^{\circ} 11.107 / 2005$.

A doutrina trazida por este artigo é de relevante importância para a conclusão do presente caso. É bastante claro o posicionamento da doutrina no sentido de que, independentemente da forma como é constituído o consórcio, este trabalha com dinheiro público. E, em se tratando de dinheiro público, torna-se obrigatório se levar em conta os preceitos públicos que concernem às entidades de sua administração indireta, pois possuem natureza autárquica.

A jurisprudência, claramente, apenas corrobora com o que diz a doutrina. Analisando os julgados, pode-se perceber o sentido que ela toma, tornando nulos os atos praticados sem a observância dos princípios públicos que regem as entidades indiretas.

\section{CONCLUSÃO}

O presente estudo elencou a formação dos consórcios públicos e quais são suas características e atribuições.

Foram apresentadas informações quanto ao que significa a cooperação entre entes federados na administração pública e que eles necessitam de cooperação mútua para atingir os resultados pretendidos, tendo em vista o alto custo da coisa pública a ser operacionalizada.

Foi possível verificar que o consórcio público fica vinculado, independente da forma, ao setor público, situando-se 
este no âmbito na administração indireta, bem como sua natureza jurídica.

Além disso, foram mostradas diversas formas existentes de consórcios públicos, mencionando tanto os consórcios que são regulamentados pela Lei $\mathrm{n}^{\mathrm{o}} 11075 / 05$ quanto os anteriores que foram formados sem legislação específica.

Constatou-se, com base nas informações pertinentes, que os consórcios públicos devem seguir os princípios da administração pública no que concerne àquilo que não é de direito privado e expressamente legalizado, como as licitações e os concursos públicos.

No entanto, o presente trabalho necessita de trabalhos futuros, principalmente no âmbito de investigação de consórcios. Sabe-se que os consórcios municipais possuem certa relutância em aplicar os preceitos inerentes às entidades públicas, tendo em vista a dificuldade que se cria na gestão em razão do engessamento por parte da necessidade de consórcios públicos, licitações, entre outras características.

Portanto, propõe-se como trabalhos futuros a necessidade de investigação in loco em consórcios públicos e uma análise da real aplicabilidade desses princípios nos consórcios municipais.

\section{REFERÊNCIAS}

ALEXANDRE, Ricardo; DEUS, João de. Direito administrativo esquematizado. São Paulo: Método, 2015.

BALDISSERA, Darlan Sampietro. Consórcios públicos intermunicipais no Brasil: panorama após os 10 anos da Lei 11.107/2005. 2015. 65 f. Dissertação (Mestrado em Administração Pública) - Fundação Getúlio Vargas, Rio de Janeiro, 2015.

BRASIL. [Constituição Federal (1967)]. Constituição da República Federativa do Brasil. Brasília, DF, 1967. Disponível em: http://www. 
planalto.gov.br/ccivil_03/Constituicao/Constituicao67.htm Acesso em: 27 mar. 2019.

BRASIL. [Constituição Federal (1988)]. Constituição da República Federativa do Brasil. Brasília, DF: Presidência da República, 1988. Disponível em: http:/www.planalto.gov.br/ccivil_03/Constituicao/ ConstituicaoCompilado.htm. Acesso em: 9 nov. 2018.

BRASIL. Decreto $\mathbf{N}^{\mathbf{0}}$ 6.017, de 17 de janeiro de 2007. Regulamenta a Lei no 11.107, de 6 de abril de 2005, que dispõe sobre normas gerais de contratação de consórcios públicos. Brasília,DF: Presidência da República, 2007. Disponível em: http://www.planalto.gov.br/ccivil_03/ Ato2007-2010/2007/Decreto/D6017.html Acesso em: 27 mar. 2019

BRASIL. Lei n⿳ 8080, de 19 de setembro de 1990. Dispõe sobre as condições para a promoção, proteção e recuperação da saúde, a organização e o funcionamento dos serviços correspondentes e dá outras providências. Brasília,DF. Disponível em: http://www.planalto.gov.br/ ccivil_03/leis/18080.htm. Acesso em: 23 fev. 2019.

BRASIL. Ministério da Saúde. Consórcios públicos intermunicipais, no âmbito do SUS: aspectos Básicos. Brasília, DF: Ministério da Saúde, 2014. Disponível em: http://portalarquivos.saude.gov.br/images/ pdf/2017/janeiro/25/11.Consorcios-Publicos-Intermunicipais-set2016. pdf. Acesso em: 22 fev. 2019.

BRASIL. Tribunal Regional do Trabalho (15. Região). Recurso ordinário: RO: 57432 SP 057432/2006. Relator: Manuel Soares Ferreira Carradita, 04 de dezembro de 2006. Disponível em: https://trt-15.jusbrasil.com.br/jurisprudencia/4540469/recurso-ordinario-ro-57432-sp-057432-2006? ref=serp . Acesso em: 22 abr. 2019

BRASIL. Tribunal Regional do Trabalho (3. Região). Recurso ordinário Trabalhista: RO 0011343-38.2017.5.03.0050 001134338.2017.5.03.0050. Relatora: Emilia Facchini, 14 agosto 2018. Disponívelem:https://trt-3.jusbrasil.com.br/jurisprudencia/614579503/ recurso-ordinario-trabalhista-ro-113433820175030050-00113433820175030050?ref=serp. Acesso em: 22 abr. 2020.

BRASIL. Tribunal Regional do Trabalho (3. Região). Recurso ordinário: RO 2706908 00184-2008-073-03-00-7. Relator: Ricardo Antonio Mohallem, 04 de fevereiro de 2009. Disponível 
em: https://trt-3.jusbrasil.com.br/jurisprudencia/614579503/ recurso-ordinario-trabalhista-ro-113433820175030050-00113433820175030050 ?ref=serp. Acesso em: 22 abr. 2019.

BRASIL. Tribunal Superior do Trabalho. Súmula no 363. A contratação de servidor público, após a CF/1988, sem prévia aprovação em concurso público, encontra óbice no respectivo art. 37 , II e $\S 2^{\circ}$, somente lhe conferindo direito ao pagamento da contraprestação pactuada, em relação ao número de horas trabalhadas, respeitado o valor da hora do salário mínimo, e dos valores referentes aos depósitos do FGTS. Brasília, DF: Tribunal Superior do Trabalho, 2011. Disponível em: http://www3.tst. jus.br/jurisprudencia/Sumulas_com_indice/Sumulas_Ind_351_400.html\#SUM-363. Acesso em: 22 abr. 2019.

COUTINHO, Frederico de M. A. Os consórcios públicos como instrumento potencializador de políticas públicas. In: ENCONTRO DA ANPAD, 30., 2006, Salvador. Anais [...]. Maringá: ANPAD, 2006.

CRESWELL, John W. Projeto de pesquisa: métodos qualitativo, quantitativo e misto. 2. ed. Porto Alegre: Artmed, 2007.

DI PIETRO, Maria Sylvia Zanella. Consórcio público na Lei No 11.107, de 6.4.2005. Revista Eletrônica de Direito do Estado, Salvador, n. 3, jul./ago./set. 2005. Disponível em: http://www.direitodoestado.com.br/ codrevista.asp?cod=40. Acesso em: 28 mar. 2019.

DI PIETRO, Maria Sylvia Zanella. Direito Administrativo. 31. ed. rev. atual e ampl. Rio de Janeiro: Forense, 2018.

MADEIRA, Carlos Guilherme; MADEIRA, Júlio César; MADEIRA, Luiz Eduardo. Consórcio público: uma análise do instrumento da Política Nacional de Resíduos Sólidos. Revista Eletrônica do Curso de Direito da UFSM, Santa Maria, v. 8, p.509-519, 4 abr. 2013. Disponível em: http://dx.doi.org/10.5902/198136948366. Acesso em: 15 mar. 2019.

MALMEGRIN, Maria Leonidia. Redes públicas de cooperação local. 3. ed. Brasília: UFSC, 2014.

MAZZA, Alexandre. Manual de Direito Administrativo. 2. ed. São Paulo: Saraiva, 2012.

MINAS GERAIS. Tribunal de Contas do Estado. Consórcios Públicos: vigência da Lei n. 11.107/2005 e quadro de pessoal. Relatora: Adriene 
Andrade. Revista do Tribunal de Contas do Estado de Minas Gerais, Belo Horizonte, v. 31, n. 4, p. 78-83, out./nov./dez. 2013.

MOREIRA NETO, Diogo de Figueiredo. Curso de direito administrativo: parte introdutória, parte geral e parte especial. 16. ed. rev. e atual. Rio de Janeiro: Forense, 2014.

PRODANOV, Cleber Cristiano; FREITAS, Ernani Cesar de. Metodologia do trabalho científico: métodos e técnicas da pesquisa e do trabalho acadêmico. 2. ed. Novo Hamburgo: Feevale, 2013. E-book. Disponível em: http://www.feevale.br/Comum/midias/8807f05a-14d0-4d5b-b1ad-1538f3aef538/E-book\%20Metodologia\%20do\%20Trabalho\%20Cientifico.pdf. Acesso em: 15 mar. 2019.

SOUZA, Franderlan Ferreira de. Breves considerações acerca dos consórcios públicos instituídos pela Lei $\mathrm{N}^{0}$ 11.107/05: oportunidades e desafios deste instrumento de cooperação federativa. Revista Eletrônica de Direito Administrativo Econômico, Salvador, n. 28, nov./dez./jan. 2012. Disponível em: http://fliphtml5.com/fdns/jnxq/basic. Acesso em: 15 mar. 2019.

VERGARA, Sylvia Constant. Projetos e relatórios de pesquisa em administração.11. ed. São Paulo: Atlas, 2009.

Recebido em: 10/12/2019

Aprovado em: 16/07/2020 